\title{
Sensibilizar Professores para o Desenvolvimento de Carreira dos Alunos: Relato de Uma Experiência
}

Sensibilizing Teachers to the Development of their Student's Careers: An Experience Report

Sensibilizar a los Profesores para el Desarrollo de la Carrera de los Alumnos: Testimonio de Una Experiencia

Íris M. Oliveira, Maria do Céu Taveira

\& Lúcia F. Neves

Universidade do

Minho, Braga -

Portugal.

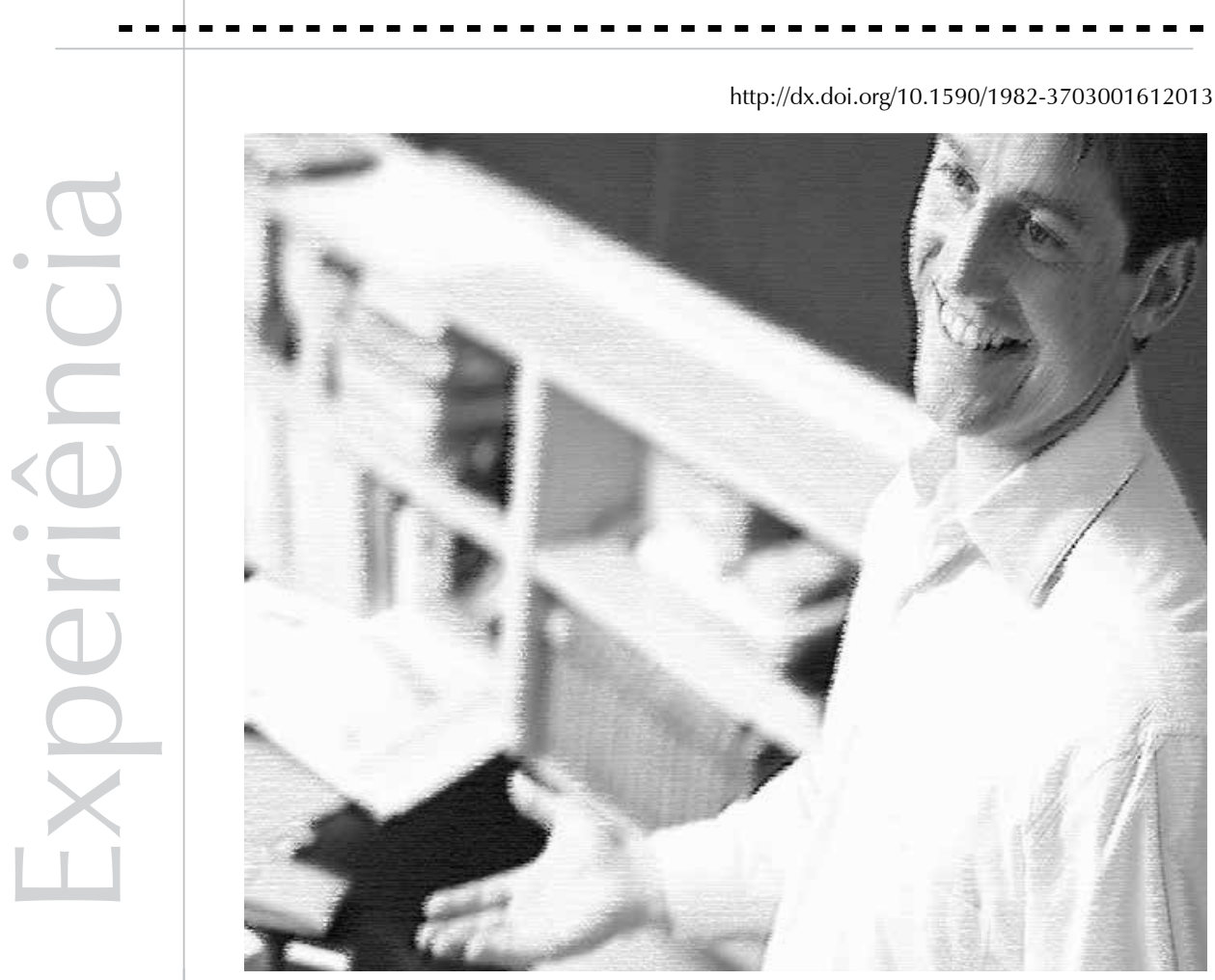


Resumo: A literatura destaca a importância de realizar sessões de sensibilização dos professores para promover a sua influência positiva e intencional, enquanto docentes, nas trajetórias de carreira dos alunos. Este artigo relata uma experiência de realização de uma sessão de sensibilização junto a professores da educação básica de um agrupamento de escolas no noroeste de Portugal. Procurou-se esclarecer o conceito de desenvolvimento de carreira junto dos professores, conscientizá-los para o papel da escola no desenvolvimento de carreira dos alunos e estimular a dinamização de atividades promotoras desse processo. Apresenta-se a estrutura da sessão, as estratégias adotadas para alcançar os objetivos propostos e as reflexões partilhadas e debatidas pelos professores. As apreciações dos intervenientes quanto à sessão de sensibilização mostraram-se favoráveis. Esta experiência ilustra a importância de realizar sessões de sensibilização dos professores nesse domínio, as quais podem sustentar a promoção do desenvolvimento de carreira dos alunos, ao longo da escolaridade.

Palavras-chave: Desenvolvimento profissional. Estudantes de ensino fundamental. Educação. Sensibilização.

Abstract: The literature highlights the importance of conducting awareness sessions for teachers to promote positive and intentional influence, as teachers in the career paths of their students. This article describes an experience of holding an outreach session with teachers of basic education of a group of schools in northwest Portugal. We sought to clarify the concept of career development among teachers, make them aware of the school's role in the career development of students, and encourage activities that promote this process. This article shows the structure of the session, the strategies adopted to achieve the proposed objectives and reflections shared and discussed by teachers. The testimonials of those who took part on the awareness session were favorable. This experience illustrates the importance of conducting awareness sessions for teachers in this field, who can sustain the promotion of career development of students throughout schooling. Keywords: Professional development. Elementary school students. Education. Sensibilizing.

Resumen: La literatura destaca la importancia de llevarse a cabo sesiones de sensibilización de los profesores para fomentar su influencia positiva e intencional, en la calidad de docentes, en las trayectorias de carrera de los alumnos. Este artículo trata de una experiencia de realización de una sesión de sensibilización junto a profesores de la educación primaria de una agrupación de escuelas en el noroeste de Portugal. Se ha buscado aclarar el concepto de desarrollo de carrera junto a los profesores, concientizarlos para la función de la escuela en el desarrollo de carrera de los alumnos y estimular la dinamización de actividades fomentadoras de ese proceso. Se presenta la estructura de la sesión, las estrategias adoptadas para lograrse los objetivos propuestos y las reflexiones compartidas y discutidas por los profesores. Las apreciaciones de los intervinientes en cuanto a la sesión de sensibilización se han mostrado favorables. Esta experiencia demuestra la importancia de llevarse a cabo sesiones de sensibilización de los profesores en ese dominio, las cuales pueden sustentar el fomento del desarrollo de carrera de los alumnos a lo largo de la escolaridad. Palabras clave: Desarrollo de carrera. Estudiantes de 1ER Grado. Educación. Sensibilización.

O desenvolvimento de carreira é um processo integrado no desenvolvimento humano que inclui a sequência de papéis desempenhados pelo indivíduo ao longo da vida e em diferentes contextos (Super, 1980). A investigação tem reforçado a concepção de desenvolvimento de carreira como processo no qual interagem fatores contextuais, desde o microssistema ao macrossistema (Vondracek, Lerner \& Schulenberg, 1986). Nas influências microcontextuais, a literatura reconhece a importância da escola no desenvolvimento de carreira dos alunos e a necessidade de aprofundar empiricamente o seu papel (Watson \& McMahon, 2005). No microcontexto escolar, os professores podem exercer um papel central no desenvolvimento de carreira dos alunos, promovendo o desenvolvimento dos seus interesses, a construção de significados acerca do trabalho e a instrumentalidade dos conteúdos curriculares (Ferreira, Nascimento \& Fontaine, 2009).

A influência dos professores no desenvolvimento de carreira dos alunos opera por meio das suas características pessoais, do domínio dos conteúdos que lecionam e das suas práticas pedagógicas (Carvalho, 2012; Pinto, Taveira, \& Fernandes, 2003). Os professores influenciam o interesse dos alunos pelas disciplinas que lecionam e por atividades relacionadas (Lerkkanen et al., 2012). Contudo, os professores tendem 
Os psicólogos escolares devem, ainda, coordenar os programas de educação para a carreira, mediar e promover a relação entre agentes educativos e a comunidade, bem como criar oportunidades de sensibilização dos professores, de modo a apoiar estes profissionais no reconhecimento da influência que exercem nas trajetórias de carreira dos alunos (Law, 1996; Sousa, 2008). a construir interações mais favoráveis às alunas e percebem mais comportamentos disruptivos dos alunos (Spilt, Koomen \& Jak, 2012). Essa evidência se destaca, já que os alunos estão em maior risco de abandono escolar e, consequentemente, de descontinuidade nas trajetórias de carreira (Ferreira, Santos, Fonseca \& Haase, 2007).

Os professores são percebidos por alunos e alunas como pessoas que: (a) ajudam a adquirir informação e identificar opções ocupacionais; (b) fornecem apoio social; (c) criam experiências de exploração; (d) moldam as suas concepções de trabalho; (e) ajudam a perceber a importância da escola; e (f) transmitem valores de vida (Schultheiss, Palma \& Manzi, 2005). Os alunos valorizam as práticas que os professores implementam para promover a sua autorregulação, a disponibilidade que mostram para responder às suas necessidades e objetivos escolares e ocupacionais, o apoio à sua exploração, tomada de decisão e planejamento de carreira, bem como a modelação de relações cooperativas com serviços da escola, pais e comunidade (Carvalho, 2012; Fouad et al., 2010; Pinto et al., 2003). Ao reconhecer a importância de promover, durante a escolaridade, o desenvolvimento de carreira dos alunos, importa perceber o papel dos professores nesse processo (Aguiar \& Conceição, 2011). O envolvimento dos professores na promoção do desenvolvimento de carreira dos alunos enquadra-se em programas de educação para a carreira. Esses programas apelam à corresponsabilização de pais, professores, profissionais da comunidade e políticos no desenvolvimento de carreira dos alunos, por meio da complementaridade dos processos de ensino-aprendizagem e de desenvolvimento de carreira (Hoyt, 1991). Os programas de educação para a carreira preveem a formação de profissionais que atuam na escola com o intuito de promover o desenvolvimento de carreira. Preveem, também, a dinamização de sessões de sensibilização para conscientizar os professores para o desenvolvimento de carreira (Law, 1996). A educação para a carreira enfatiza o papel da escola na construção de ligações a contextos envolventes, bem como na promoção da aprendizagem contínua dos alunos e de competências transversais (Taveira, 1998).

Os psicólogos escolares assumem um papel central na preparação e implementação de programas de educação para a carreira. Esses profissionais podem sensibilizar professores para o desenvolvimento de carreira, promover o empoderamento dos agentes educativos e da parceria escola-família na influência das trajetórias de carreira dos alunos e conscientizar a comunidade escolar para a reciprocidade entre o desenvolvimento de carreira e acadêmico (Araújo, 2004; Baptista \& Costa, 2004). Os psicólogos escolares devem, ainda, coordenar os programas de educação para a carreira, mediar e promover a relação entre agentes educativos e a comunidade, bem como criar oportunidades de sensibilização dos professores, de modo a apoiar estes profissionais no reconhecimento da influência que exercem nas trajetórias de carreira dos alunos (Law, 1996; Sousa, 2008). Os psicólogos escolares podem desenvolver também, diretamente com os alunos, atividades previstas de educação para a carreira. Nesse caso, o modelo de intervenção de carreira apresenta-se sob uma estratégia aditiva, realizada em espaço e tempo extracurriculares próprios.

A legislação do Sistema Educativo Português considera, de forma explícita ou implícita, a importância de promover o desenvolvimento de carreira dos alunos (Decreto-Lei no 139/2012; Lei no 46/86). Contudo, a instabilidade profissional atualmente vivida nas escolas, a escassa preparação dos professores no âmbito da educação para a carreira e as dificuldades em criar formações creditadas dificultam a implementação sistemática desses programas em Portugal (Sousa, 2008). 
1 Em Portugal, o ensino básico é composto por três ciclos de ensino. O primeiro ciclo corresponde aos primeiros quatro anos de escolaridade. O segundo ciclo corresponde ao $5^{\circ}$ e $6^{\circ}$ anos de escolaridade. O terceiro ciclo corresponde ao $7 \stackrel{0}{ }, 8^{\circ}$ e 9 o anos de escolaridade. Até ao presente ano letivo, o ensino básico

completo corresponde à escolaridade obrigatória. No próximo ano letivo, em Portugal, a escolaridade obrigatória exigirá estudos até ao $12^{\circ}$ ano de escolaridade (ensino secundário).

Em Portugal, o ensino básico é composto por três ciclos de ensino. O primeiro ciclo corresponde aos primeiros quatro anos de escolaridade. O segundo ciclo corresponde ao $5^{\circ}$ e $6^{\underline{0}}$ anos de escolaridade. O terceiro ciclo corresponde ao 7 을 $8^{\circ}$ e $9^{\circ}$ anos de escolaridade. Até ao presente ano letivo, o ensino básico completo corresponde à escolaridade obrigatória. No próximo ano letivo, em Portugal, a escolaridade obrigatória exigirá estudos até ao $12^{\circ}$ ano de escolaridade (ensino secundário).
Considerando tais limitações, este artigo relata uma experiência de sensibilização de professores do ensino básico ${ }^{1}$ para o desenvolvimento de carreira. Pretendese estimular os psicólogos a dinamizar práticas de sensibilização de professores nessa área para criar condições favoráveis à implementação sistemática de estratégias de educação para a carreira em Portugal.

\section{Objetivos da sessão de sensibilização}

A sessão de sensibilização relatada neste artigo foi enquadrada em um programa de formação creditada para professores do ensino básico, "Empreendedorismo e vida ativa", desenvolvido por um agrupamento de escolas públicas no noroeste de Portugal. O programa de formação foi promovido pela psicóloga do agrupamento de escolas em colaboração com a Junior Achievement Portugal (2008). Essa associação cria parcerias com escolas para dinamizar ações educativas promotoras do empreendedorismo de jovens. Essas parcerias incluem também a realização de um programa de formação para professores. Esse programa foi planejado e coordenado pela psicóloga escolar (Serviço de Psicologia e Orientação, 2011), com o apoio de um centro de formação (Ancornet, 2008), que cedeu os contactos dos professores e um espaço para a formação.

O programa de formação procurou promover, junto dos professores, atitudes positivas quanto ao futuro, estimular o trabalho cooperativo na comunidade escolar e aproximar a escola de contextos laborais. Para alcançar esses objetivos, o programa de formação integrou uma sessão de sensibilização para o desenvolvimento de carreira. Assim, dinamizou-se a sessão de sensibilização "Desenvolvimento de carreira: Caracterização e importância da escola", relatada neste artigo.

A sessão teve como objetivos: (1) esclarecer e ilustrar o conceito de desenvolvimento de carreira junto dos professores; (2) conscientizar os professores para o papel que exercem no desenvolvimento de carreira dos alunos; e (3) favorecer o empoderamento dos professores na condução de atividades que visam promover, de forma positiva e intencional, o desenvolvimento de carreira dos alunos, sob coordenação de um psicólogo escolar.

\section{Descrição da sessão de sensibilização}

\section{Professores-alvo}

Participaram da sessão 18 professores, sendo $14(77.78 \%)$ mulheres e quatro (22.22\%) homens. A idade dos professores varia entre os 40 e os 60 anos ( $M=49.78, D P=5.95)$. Dezesseis professores (88.89\%) pertencem ao quadro de pessoal do agrupamento de escolas e dois $(11.11 \%)$ pertencem ao quadro de pessoal da zona pedagógica. Os(as) professores(as) lecionam as disciplinas de Português, Inglês, Francês, Matemática, Ciências Naturais, Físico-Química, História e Geografia de Portugal, Educação Visual e Educação Física no $2^{\circ}$ e 3.ำ ciclos do ensino básico português.

\section{Procedimentos}

A psicóloga escolar efetuou um convite a uma técnica pós-graduada em Psicologia Escolar, a frequentar atualmente o doutoramento em Psicologia Aplicada, para dinamizar uma sessão de sensibilização para o desenvolvimento de carreira. Após aceitação do convite, a data, hora e local da sessão foram negociados com a diretora do agrupamento de escolas, com a psicóloga escolar e com a responsável pelo centro de formação de professores relacionado. A psicóloga escolar informou aos professores inscritos no programa de formação "Empreendedorismo e vida ativa" sobre a sessão de sensibilização, com quinze dias de antecedência, pessoalmente e via e-mail. 
A apresentação de mudanças no mundo de trabalho enquadrou a necessidade de redefinir modelos clássicos de intervenção de carreira, apoiados em modelos traço-e-fator, adequandoos aos atuais desafios laborais e socioeconômicos e considerando perspetivas desenvolvimentistascontextualistas de carreira (Leão, 2006).
A sessão de sensibilização ocorreu em abril de 2013, durante 90 minutos, no período não letivo dos professores. A sessão foi apoiada por uma apresentação em powerpoint preparada pela dinamizadora. No final, solicitou-se aos professores que registrassem as suas apreciações sobre a sessão em uma ficha anônima. A ficha foi elaborada pela dinamizadora da sessão, incluíndo quatro questões respondidas em uma escala de 1 "Nada" a 4 "Muito" e duas questões de resposta aberta. As questões focaram o grau de satisfação com a sessão, o grau de utilidade percebido da mesma para a atualização de conhecimentos, o grau de eficácia na abordagem dos tópicos e os aspetos dos quais gostaram mais e menos. Pediu-se também à psicóloga escolar que enviasse por e-mail as suas impressões. A dinamizadora da sessão registrou também as suas apreciações em papel.

\section{Estrutura}

A sessão de sensibilização estruturou-se por meio da abordagem de três questões centrais: (1) O que é o desenvolvimento de carreira? (2) Qual a importância da escola no desenvolvimento de carreira dos alunos?

(3) É possível promover o desenvolvimento de carreira dos alunos?

\section{Temas}

\section{O que é o desenvolvimento de carreira?}

A primeira questão procurou esclarecer e ilustrar o conceito de desenvolvimento de carreira. Atendendo a que as sessões de sensibilização devem valorizar os conhecimentos prévios dos professores (Timperley, Wilson, Barrar, \& Fung, 2007), introduziu-se o conceito de desenvolvimento de carreira por meio do enquadramento em face das mudanças globais no mundo de trabalho, com as quais os professores se deparam no seu cotidiano. Enunciaram-se algumas mudanças no mundo de trabalho, focando a atual instabilidade, imprevisibilidade e necessidade de investir na aprendizagem contínua (Pinto, 2010).

A apresentação de mudanças no mundo de trabalho enquadrou a necessidade de redefinir modelos clássicos de intervenção de carreira, apoiados em modelos traço-e-fator, adequando-os aos atuais desafios laborais e socioeconômicos e considerando perspetivas desenvolvimentistas-contextualistas de carreira (Leão, 2006). Assim, procurou-se desmistificar duas concepções errôneas apresentadas pelos professores sobre a intervenção de carreira. A primeira considera que a intervenção de carreira ocorre pontualmente para apoiar os alunos em momentos de tomada de decisão esperadas pelo Sistema Educativo (Leão, 2006). Procurou-se desmistificar tal concepção na sessão, à luz de perspetivas desenvolvimentistas-contextualistas que sustentam intervenções de carreira no ciclo vital e que valorizam os contextos de vida (Taveira, 1998). Essas perspetivas de carreira consideram, ainda, momentos de tomada de decisão esperados e não esperados no atual contexto de trabalho de maior insegurança (Baptista \& Costa, 2004; Pinto, 2010).

A segunda concepção errônea considera que a intervenção de carreira se foca no uso de medidas de avaliação de interesses e aptidões dos alunos, de modo a Ihes apresentar informação sobre opções que poderão corresponder a esse perfil (Leão, 2006). Procurou-se desmistificar essa concepção na sessão de sensibilização, com base no conceito de desenvolvimento de carreira e em exemplos de atividades que podem promover o desenvolvimento de carreira dos alunos, sistematicamente e a partir da articulação entre agentes educativos e a comunidade (Taveira, 1998).

Esse enquadramento permitiu apresentar uma definição de desenvolvimento de carreira enquanto processo dinâmico, integrado no 
desenvolvimento humano, que engloba a aquisição de competências de carreira, a aprendizagem acerca do mundo de trabalho e a sequência de papéis que o indivíduo desempenha em múltiplos contextos ao longo da vida (Super, 1980).

O conceito de desenvolvimento de carreira foi aplicado aos períodos de vida da infância, adolescência, idade adulta e velhice (Super, 1980). Na infância, destacou-se que as crianças realizam aprendizagens sobre si próprias e o mundo envolvente, na escola e na família, bem como integram conceitos de gênero e classe social, os quais podem conduzir à circunscrição precoce de alternativas de carreira (Gottfredson, 1981; Watson \& McMahon, 2005).

Na adolescência, salientou-se que a exploração orientada para o self e para o meio favorece o desenvolvimento do autoconceito e o ensaio em fantasia, cognitivo ou real de alternativas de carreira (Super, 1980; Taveira, 2001).

$\mathrm{Na}$ idade adulta, consideraram-se esforços dos indivíduos em implementar o seu autoconceito em opções de carreira, em ingressar e se manter em postos de trabalho, em construir um estilo de vida e em gerir papéis de vida (Ferreira, Taveira, \& Saavedra, 2009; Super, 1980).

Na velhice, referiu-se a importância da preparação da aposentadoria e dos desafios que se podem colocar na redefinição do autoconceito e do estilo de vida (Super, 1980).

A aplicação do conceito de desenvolvimento de carreira em diferentes períodos de vida procurou caracterizar esse processo em função de tarefas de carreira. Procurou, ainda, relacionar tarefas de carreira em períodos de vida específicos com experiências ocupacionais e não ocupacionais dos professores. Em particular, tentou-se complementar a caracterização do desenvolvimento de carreira na infância e adolescência com experiências relacionais dos professores com seus filhos e alunos. Relacionaram-se, ainda, as tarefas de carreira na idade adulta e velhice com experiências interpessoais dos professores com seus familiares, pares, colegas e chefes.

A ilustração do conceito de desenvolvimento de carreira incluiu curiosidades sobre três celebridades: (1) O inventor da lâmpada, Thomas Edison, tinha medo do escuro quando era criança; (2) A apresentadora Oprah, aos três anos de idade, era estimulada a falar em público, na igreja, pela sua avó; e (3) Cristiano Ronaldo começou a jogar futebol na rua, aos oito anos. Perguntou-se aos professores em que medida essas curiosidades poderiam espelhar o conceito de desenvolvimento de carreira previamente apresentado. Os professores refletiram sobre a importância de experiências precoces em contextos como a família e a vizinhança no desenvolvimento de carreira das celebridades. Concluíram que o desenvolvimento de carreira pode incluir a interação entre o potencial inato e as experiências contextuais, sendo que os contextos de vida podem estimular o aperfeiçoamento do potencial inato dos indivíduos e atribuições ao esforço.

\section{Qual a importância da escola no desenvolvimento de carreira dos alunos?}

A segunda questão procurou favorecer a conscientização dos professores quanto ao papel que escola exerce no desenvolvimento de carreira dos alunos. Para introduzir essa questão, reviram-se passagens da legislação do Sistema Educativo Português, com as quais os professores estão familiarizados devido à sua experiência profissional. A primeira passagem - "o sistema educativo responde às necessidades resultantes da realidade social, contribuindo para o desenvolvimento 
pleno e harmonioso da personalidade dos indivíduos, incentivando a formação de cidadãos livres, responsáveis, autónomos e solidários e valorizando a dimensão humana do trabalho" (Lei no 46/86, p. 3068) procurou, por um lado, reforçar a concepção de desenvolvimento de carreira como um processo contextualmente influenciado e integrado no desenvolvimento humano. Por outro lado, essa passagem considerou que a educação é um veículo pelo qual se prevê a promoção do desenvolvimento de carreira dos alunos. A segunda passagem visou enquadrar a diversidade de ofertas educativas do Sistema Educativo Português nas estratégias políticas:

Diversidade de ofertas educativas, tomando em consideração as necessidades dos alunos, por forma a assegurar a aquisição de conhecimentos e o desenvolvimento de capacidades essenciais para cada ciclo e nível de ensino, bem como as exigências decorrentes das estratégias de desenvolvimento do País (Decreto-Lei no 139/2012, p. 3477)

As passagens da legislação do Sistema Educativo Português estimularam os professores a concluir que a escola serve os interesses estratégicos do país, devendo existir uma relação recíproca entre a educação, o desenvolvimento de carreira e a cidadania. Os professores questionaram, ainda, se a escola é importante na preparação dos alunos para o seu futuro ingresso e manutenção no mercado laboral, ou se assume um papel passivo nesse processo, devido à imprevisibilidade laboral.

No seguimento das impressões partilhadas pelos professores, apresentaram-se evidências sobre o papel da escola no desenvolvimento de carreira dos alunos. A investigação foi organizada em três eixos: rendimento acadêmico; papel dos professores; e papel da escola, como instituição organizacional. No primeiro eixo, focou-se na evidência de que o rendimento acadêmico dos alunos se relaciona com as suas intenções em prosseguir estudos, o significado que constroem e atribuem à escola, o envolvimento escolar, as suas expectativas de autoeficácia de carreira e em diferentes disciplinas e o bem-estar (Lemos, Almeida \& Primi, 2007; Lewis, Huebner, Malone \& Valois, 2011; Ribeiro, Almeida \& Gomes, 2006). Essas evidências suscitaram a preocupação em evitar que alunos que apresentam menor rendimento acadêmico se alienem do currículo e se percebam como pouco eficazes no alcance de resultados escolares e profissionais desejados. Em face dessa preocupação, destacou-se a pertinência de criar oportunidades para que os alunos transfiram conhecimentos acadêmicos para práticas cotidianas e profissionais, sob supervisão de professores, psicólogos escolares e outros profissionais da comunidade (Schultheiss, 2005).

No segundo eixo de investigação, reconheceu-se que os professores, muitas vezes não intencionalmente, influenciam o desenvolvimento de carreira dos alunos por meio das suas características pessoais, do domínio dos conteúdos que lecionam e das suas práticas pedagógicas (Pinto et al., 2003). A relação de proximidade com os alunos suporta a influência dos professores na transmissão de valores de vida aos alunos, na sustentação de interesses por domínios de atividade relacionados com disciplinas lecionadas, na construção de significados sobre o trabalho, na promoção da instrumentalidade percebida dos conteúdos programáticos e na identificação de opções de carreira (Ferreira et al., 2009; Lerkkanen et al., 2012; Pinto et al., 2003). A influência dos professores no desenvolvimento de carreira dos alunos pode compreenderse por meio da qualidade da interação professor-aluno e da concepção dos alunos acerca dos professores (Schultheiss et al., 2005). Esse segundo eixo de investigação gerou surpresa aos participantes na sessão, podendo ter contribuído para o seu insight sobre a importância das interações entre professores e alunos. 
Ao perspectivar a escola como instituição, os professores concluíram que as estratégias escolares devem ser adequadas aos atuais desafios sociais, de modo a sustentar um papel ativo e adaptativo da parte dos alunos.
No terceiro eixo de investigação, considerouse que a escola, enquanto organização, enquadra ações dos professores e dos alunos. Reconheceu-se que um estilo de liderança transformacional e um clima escolar de aceitação potenciam a criação de oportunidades estruturadas que reforçam o papel ativo dos alunos e que promovem a exploração ocupacional, a preocupação com o futuro escolar e profissional, a criatividade e competências de resolução de problemas (Aron, Milicic \& Armijo, 2012; Noack, Kracke, Gniewosz \& Dietrich, 2010). Os resultados empíricos integrados nesse terceiro eixo de investigação estimularam os professores a refletirem acerca do enquadramento estratégico da escola. Ao perspectivar a escola como instituição, os professores concluíram que as estratégias escolares devem ser adequadas aos atuais desafios sociais, de modo a sustentar um papel ativo e adaptativo da parte dos alunos. Reconheceram também a centralidade da instituição escolar no acolhimento de alunos provenientes de meios socioeconômicos desfavorecidos e que apresentam baixo rendimento acadêmico em relação à promoção do seu desenvolvimento integral.

\section{É possível promover o desenvolvimento de carreira dos alunos?}

A terceira questão visou empoderar os professores para a promoção intencional do desenvolvimento de carreira dos alunos. Enunciaram-se quatro atividades que poderão ser conduzidas pelos professores sob coordenação de um psicólogo escolar.

A primeira atividade sugeriu que se convidassem encarregados de educação para apresentar o que fazem no seu dia a dia. Nessas apresentações, seria possível abordar a vida de trabalho remunerado e não remunerado dos encarregados de educação, considerando quais as atividades que efetuam diariamente, como e onde as desempenham, que significados Ihes atribuem e que sentimentos emergem quando da sua realização. Essa atividade permitiria favorecer a parceria escola-família na criação de oportunidades de exploração e de obtenção de informação sobre diferentes atividades profissionais e domésticas existentes na comunidade por parte dos alunos (Araújo, 2004; Schultheiss, 2005). Os professores consideraram se seria pertinente convidar encarregados de educação que realizam atividades ocupacionais e não ocupacionais semelhantes ou diferentes. Concluiu-se que, inicialmente, seria importante criar oportunidades de contacto com encarregados de educação que desempenham atividades diferentes, avançando ao longo da escolaridade para o convite de encarregados de educação ou de outros profissionais da comunidade que desempenham atividades semelhantes e de interesse para os alunos (Porfeli \& Skorikov, 2010). No âmbito de ações educativas promovidas pela Junior Achievment Portugal, os professores referiram que alguns alunos tinham contatado, em sala de aula, com profissionais da comunidade que lhes apresentaram o seu dia a dia. Nessas apresentações, os professores reconheceram que os alunos valorizaram o entusiasmo com que os conteúdos eram abordados, mostrando-se mais predispostos a explorar atividades inerentes a maior entusiasmo e afetos positivos.

A segunda atividade apelou para a criação de oportunidades de exploração de trabalhos remunerados ou não remunerados tradicionalmente associados a homens ou mulheres. Considerou-se a possibilidade de convidar encarregados de educação ou profissionais da comunidade que desempenham trabalhos mais típicos do sexo oposto, a apresentar o que fazem no dia a dia. Essa atividade permitiria desafiar estereótipos de gênero, criar oportunidades de exploração igualitária de trabalhos, promover a autoeficácia em atividades tradicionalmente relacionadas ao sexo oposto e prevenir a circunscrição precoce de opções ocupacionais (Gottfredson, 1981; Saavedra, Taveira, \& Silva, 2010). 
Ilustrou-se a pertinência dessa sugestão mediante dois exemplos: (1) existem poucos homens educadores de infância e (2) apesar das alunas apresentarem bons resultados acadêmicos em Matemática, evitam a Engenharia. Destacou-se a necessidade de oferecer modelos de profissionais que optaram por alternativas escolares e profissionais mais típicas do sexo oposto, de modo a que os alunos possam reconhecer a possibilidade de construir uma trajetória de carreira além de trilhos tipicamente femininos ou masculinos (Saavedra et al., 2010). Os professores sugeriram, ainda, rentabilizar contatos com antigos alunos do agrupamento de escolas que exercem atividades tradicionalmente associadas ao sexo oposto, de modo a partilharem as suas experiências com os atuais alunos.

A terceira atividade apelou para a explicitação da aplicabilidade prática de conteúdos curriculares. Considerou-se uma aula de inglês em que se ensina o nome dos alimentos. Indicou-se que o professor poderia explicitar a aplicabilidade prática do conteúdo, referindo que pessoas que trabalham em restaurantes precisam saber os alimentos em inglês para responder a pedidos de clientes estrangeiros. Referiu-se, ainda, que poderia existir algum aluno cujos familiares se tivessem confrontado com essa situação, podendo complementar a partilha de experiências ilustrativas da aplicabilidade prática de conteúdos curriculares. Essa atividade promoveria a transferência de conteúdos escolares para o cotidiano (Ferreira et al., 2009; Schultheiss, 2005). Os professores reconheceram também a importância de planejar visitas de estudo, para os alunos perceberem o seu enquadramento escolar e o contributo social de diferentes conhecimentos e profissões.

A quarta atividade propôs apoiar os alunos a identificar os papéis de vida que desempenham em diferentes contextos. Exemplificou-se essa sugestão por meio do apoio a um aluno na elaboração de um calendário de estudo. Ao elaborar esse calendário, poderia estimular-se o aluno a identificar os locais onde está no dia a dia, a registrar o tempo que dedica a cada contexto e papel (e.g., estudante, filho, desportista) e o tempo restante para realizar atividades escolares. Indicou-se que os alunos podem beneficiar de apoio na gestão de papéis de vida, de modo a os gerirem eficazmente. Essa aprendizagem é central para a gestão de papéis de vida em idades posteriores (e.g., gestão de papéis profissionais e familiares na idade adulta). Essa atividade promoveria a conscientização dos papéis de vida que os alunos desempenham em diferentes contextos e favoreceria aprendizagens quanto à antecipação de conflitos de papéis em momentos de tomada de decisão (Ferreira et al., 2009; Schultheiss, 2005). Uma vez que os professores podem apoiar alunos na elaboração de um calendário de estudo, considerou-se que essa atividade poderá ser infundida nessas práticas.

\section{Apreciações quanto à sessão de sensibilização}

\section{Apreciações dos professores}

Em relação à satisfação com a sessão, 13 (72.2\%) professores referiram estar muito satisfeitos e cinco (27.8\%) satisfeitos. Quanto ao grau de utilidade da sessão para a atualização de conhecimentos, oito (44.4\%) participantes perceberam a sessão como muito útil e 10 (55.5\%) como útil. Tendo em conta o grau de eficácia da sessão no esclarecimento do conceito de desenvolvimento de carreira, 11 (61.1\%) participantes consideraram a sessão muito eficaz e sete (38.9\%) consideraram-na eficaz. Em relação ao grau de eficácia da sessão na abordagem da importância da escola no desenvolvimento de carreira dos alunos, nove professores (50\%) apreciaram a sessão como muito eficaz e nove (50\%) como eficaz. 
Doze $(66.67 \%)$ e seis $(33.33 \%)$ professores referiram os aspetos de que gostaram mais e menos na sessão, respectivamente. Os aspetos de que mais gostaram incluíram: o tema; a clareza da sessão; a reflexão sobre o papel da escola em face das atuais mudanças no mundo de trabalho; o debate de impressões sobre os conteúdos; e as sugestões de atividades que se poderiam implementar. Os aspetos de que menos gostaram referiramse: ao escasso tempo para aprofundar os conteúdos; à hora de realização da sessão; e ao não aprofundamento de práticas sugeridas já implementadas.

\section{Apreciações da psicóloga escolar}

A psicóloga escolar apreciou favoravelmente a sessão de sensibilização. A profissional considerou que a sessão teve um bom enquadramento teórico, com informação em quantidade e qualidade adequada aos objetivos. A sessão ilustrou a importância da escola e, em particular, dos professores no desenvolvimento de carreira dos alunos com exemplos concretos, o que foi útil. A psicóloga escolar considera que valerá a pena aprofundar algumas das sugestões práticas apresentadas para futuramente as implementar em contexto escolar.

\section{Apreciação da dinamizadora da sessão de sensibilização}

A dinamizadora apreciou positivamente a sessão, considerando que foi enriquecida pelos exemplos fornecidos, permitindo ilustrar os tópicos abordados, relacioná-los com as mudanças no mundo de trabalho e estimular a participação dos professores. A estrutura da apresentação mostrou-se também adequada para alcançar os objetivos propostos. Conclui-se que importará detalhar as atividades sugeridas por meio da partilha de materiais (e.g., fichas de trabalho, vídeos).

\section{Conclusão}

A experiência relatada salienta a importância dos psicólogos escolares sensibilizarem professores para o desenvolvimento de carreira, de modo a construírem uma relação de parceria profissional eficaz na promoção do desenvolvimento de carreira dos alunos ao longo da escolaridade (Araújo, 2004; Baptista \& Costa, 2004; Sousa, 2008).

A estrutura da sessão de sensibilização foi adequada para alcançar os objetivos propostos. A valorização de experiências dos professores (Timperley et al., 2007) revelou-se útil para estimular a sua reflexão quanto aos tópicos abordados.

As apreciações favoráveis dos professores, da psicóloga escolar e da dinamizadora da sessão apontam para a pertinência de abordar sistematicamente e de forma estruturada este tema junto dos professores. Apelam, ainda, para a necessidade de aprofundar práticas promotoras do desenvolvimento de carreira dos alunos, conciliando contributos da teoria, da investigação e da prática em sessões de sensibilização (Super, 1980).

As atividades sugeridas e as impressões dos intervenientes reforçam a centralidade da escola no desenvolvimento de carreira dos alunos e o papel promissor dos psicólogos escolares enquanto mobilizadores da corresponsabilização de encarregados de educação, professores, profissionais da comunidade e governantes políticos pelo desenvolvimento de carreira dos alunos, tal como prevêem os programas de educação para a carreira (Hoyt, 1991; Law, 1996; Taveira, 1998). A experiência relatada pretende estimular os psicólogos escolares a investirem na sensibilização dos professores para o desenvolvimento de carreira (Law, 1996) e a coordenar práticas de promoção do desenvolvimento de carreira dos alunos (Pinto et al., 2003). Assume-se que este trabalho apoiará a implementação sistemática de programas de educação para a carreira em Portugal. 


\section{Íris M. Oliveira}

Doutoranda em Psicologia Aplicada pela Universidade do Minho, Braga - Portugal.

E-mail: ioliveira@psi.uminho.pt

\section{Maria do Céu Taveira}

Doutora em Psicologia Escolar pela Universidade do Minho. Docente da Universidade do Minho, Braga Portugal.

E-mail: ceuta@psi.uminho.pt

\section{Lúcia F. Neves}

Doutora em Psicologia Clínica e psicóloga escolar e educacional de um agrupamento de escolas públicas no norte de Portugal, Braga - Portugal.

E-mail: spo.esod08@gmail.com

Endereço para envio de correspondência:

Centro de Investigação em Psicologia, Universidade do Minho, Campus de Gualtar. CEP: 4710-057. Braga, Portugal.

Recebido 22/07/2013, 1a Reformulação 09/12/2013, Aprovado 10/12/2013.

Aguiar, F. H., \& Conceição, M. I. (2011). Orientação vocacional como tema transversal: Uma experiência com profissionais da educação. Revista Brasileira de Orientação Profissional, 12(1), 107-117. Recuperado de http://pepsic.bvsalud.org/scielo. php?pid=S1679-33902011000100012\&script=sci_arttext

Ancornet. (2008). Centro de formação contínua Gaia nascente [Página Web]. Recuperado de http://www.cfgaianascente. edu.pt

Araújo, S. B. (2004). Desenvolvimento vocacional na infância: Conclusões e orientações gerais para uma intervenção vocacional precoce. In M. C. Taveira, H. Coelho, H. Oliveira, \& J. Leonardo (Eds.), Desenvolvimento vocacional ao longo da vida: Fundamentos, princípios e orientações (pp. 36-42). Coimbra: Almedina.

Aron, A. M., Milicic, N., \& Armijo, I. (2012). Clima social escolar: Una escala de evaluación Escala de Clima Social Escolar, ECLIS. Universitas Psychologica, 11(3), 803-813. Recuperado de http://revistas.javeriana.edu.co/sitio/psychologica/sccs/ articulo.php?id=749

Baptista, C. M., \& Costa, J. A. (2004). O desenvolvimento vocacional numa perspetiva de integração curricular. In
M. C. Taveira, H. Coelho, H. Oliveira, \& J. Leonardo (Eds.) Desenvolvimento vocacional ao longo da vida: Fundamentos, princípios e orientações (pp. 171-180). Coimbra: Almedina.

Carvalho, M.S. (2012). A implementação de decisões vocacionais no ensino secundário: Contributos para a construção de um modelo de intervenção. Dissertação de Doutorado, Escola de Psicologia Universidade do Minho, Braga, Portugal. Recuperado de http:// repositorium.sdum.uminho.pt/handle/1822/23536

Decreto-Lei número 139/2012. (2012, 5 jul.) Diário da República, 1․ Série, número 129.

Ferreira, A. F., Nascimento, I., \& Fontaine, A. M. (2009). O papel do professor na transmissão de representações acerca de questões vocacionais. Revista Brasileira de Orientação Profissional, 10(2), 43-56. Recuperado de http://www.redalyc.org/articulo. oa?id=203014923006

Ferreira, J. A., Santos, E. J. R., Fonseca, A. C., \& Haase, R. (2007) Early predictors of career development: A 10-year follow-up study. Journal of Vocational Behavior, 70(1), 61-77. doi: http:// dx.doi.org/10.1016/j.jvb.2006.04.006 
Referências
Ferreira, S., Taveira, M.C., \& Saavedra, L. (2009). Trabalho e família: Esferas necessariamente divergentes ou potencialmente convergentes? Psicologia, Educação e Cultura, 13(1), 105-120.

Fouad, N. A., Hackett, G., Smith, P. L., Kantamneni, N., Fitzpatrick, M., Haag, S., \& Spencer, D. (2010). Barriers and supports for continuing in mathematics and science: Gender and educational level differences. Journal of Vocational Behavior, 77(3), 361-373. doi: http://dx.doi.org/10.1016/j. jvb.2010.06.004

Gottfredson, L. (1981). Circumscription and compromise: A developmental theory of occupational aspirations. Journal of Counseling Psychology, 28(6), 545-579. doi: http://dx.doi. org/10.1037/0022-0167.28.6.545

Hoyt, K. B. (1991). The concept of work: Bedrock for career development. Future Choices, 2, 23-30.

Junior Achievement Portugal. (2008). Junior achievement Portugal: Aprender a empreender [Página Web]. Recuperado de http://portugal.ja-ye.org/

Law, B. (1996). Staff development. In T. Watts, B. Law, J. Killeen, J. Kidd, \& R. Hawthorn (Eds.), Rethinking careers, education and guidance: Theory, policy and practice (pp. 287-306). London: Routledge.

Leão, P. (2006). A promoção do desenvolvimento vocacional em contexto escolar: $\mathrm{O}(\mathrm{s})$ tempo(s) e o(s) modo(s). Revista Portuguesa de Investigação Educacional, 5, 63-78. Recuperado de http://www.iccdpp.org/Portals/1/School\%20 guidance\%20Portugal\%20P\%20Leao1007.pdf

Lei número 46/86. (1986, 14 out.) Diário da República, 1ạ Série, número 237 ,

Lemos, G., Almeida, L. S., \& Primi, R. (2007). Habilidades cognitivas, desempenho académico e projetos vocacionais: Estudo com alunos portugueses do 5.o ao 12. ano. In A. Barca, M. Peralbo, A. Porto, B. Duarte da Silva, \& L. Almeida (Eds.), Libro de Actas do IX Congreso Internacional GalegoPortugués de Psicopedagoxia (pp. 1784-1793). Coruña: Revista Galego-Portuguesa de Psicoloxía e Educación.

Lerkkanen, M., Kiuru, N., Pakarinen, E., Viljaranta, J., Poikkeus, A., Rasku-Puttonen, H., Seikkinen, M., \& Nurmi, J. (2012). The role of teaching practices in the development of children's interest in reading and mathematics in kindergarten. Contemporary Educational Psychology, 37(4), 269-279. doi: http://dx.doi.org/10.1016/j.cedpsych.2011.03.004

Lewis, A. D., Huebner, E. S., Malone, P. S., \& Valois, R. (2011). Life satisfaction and student engagement in adolescents. Journal of Youth Adolescence, 40, 249-262. doi: http://dx.doi. org/10.1007/s10964-010-9517-6

Noack, P., Kracke, B., Gniewosz, B. \& Dietrich, J. (2010). Parental and school effects on students' occupational exploration: A longitudinal and multilevel analysis. Journal of Vocational Behavior, 77 (1), 50-57. doi: http://dx.doi.org/10.1016/j. jvb.2010.02.006

Pinto, H.R. Taveira, M.C. \& Fernandes, M.E. (2003). Os professores e o desenvolvimento vocacional dos estudantes. Revista Portuguesa de Educação, 16(1), 37-58.

Pinto, J. C. (2010). Gestão pessoal da carreira: Estudo de um modelo de intervenção psicológica com bolseiros de investigação. Dissertação de Doutorado, Escola de Psicologia, Universidade do Minho, Braga, Portugal. Recuperado de http://repositorium.sdum.uminho.pt/handle/1822/11633

Porfeli, E. J., \& Skorikov, V. B. (2010). Specific and diverse career exploration during late adolescence. Journal of Career Assessment, 18(1), 46-58. doi: http://dx.doi. org/10.1177/1069072709340528

Ribeiro, I., Almeida, L. S., \& Gomes, C. (2006). Conhecimentos prévios, sucesso escolar e trajetórias de aprendizagem: Do 1.․․ para o 2.․ ciclo do ensino básico. Avaliação Psicológica, 5(2), 127-133. Recuperado de http://pepsic.bvsalud.org/scielo. php?pid =S1677-04712006000200002\&script=sci_arttext

Saavedra, L., Taveira, M.C., \& Silva, A.D. (2010). A subrepresentatividade das mulheres em áreas tipicamente masculinas: Factores explicativos e pistas para a intervenção. Revista Brasileira de Orientação Profissional, 11(2), 49-60. Recuperado em de: http://repositorium.sdum.uminho.pt/ handle/1822/11636

Schultheiss, D. (2005). Elementary career intervention programs: Social action initiatives. Journal of Career Development, 31(3), 185-194. doi: http://dx.doi. org/10.1177/089484530503100303

Schultheiss, D., Palma, T., \& Manzi, A. (2005). Career development in middle childhood: A qualitative inquiry. The Career Development Quarterly, 53(3), 246-252. doi: http:// dx.doi.org/10.1002/j.2161-0045.2005.tb00994.x

Serviço de Psicologia e Orientação. (2011). Serviço de Psicologia e Orientação [Página Web]. Recuperado de: http://spo-esod. webnode.pt/

Sousa, S. C. (2008). Educação para a carreira na educação pré-escolar: Avaliação da eficácia de uma intervenção de consultoria psicológica. Dissertação de Mestrado, Instituto de Educação e Psicologia, Universidade do Minho, Braga, Portugal.

Spilt, J. L., Koomen, H. M., \& Jak, S. (2012). Are boys better off with male and girls with female teachers? A multilevel investigation of measurement invariance and gender match in teacher-student relationship quality. Journal of School Psychology, 50(3), 363-378. doi: http://dx.doi.org/10.1016/j. jsp.2011.12.002

Super, D. E. (1980). A life-span, life-space approach to career development. Journal of Vocational Behavior, 16, 282-298. doi: http://dx.doi.org/10.1016/0001-8791(80)90056-1

Taveira, M.C. (1998). Desenvolvimento vocacional nos primeiros anos da adolescência: Teoria e prática. Saberes da Casa Pia de Lisboa, 9, 33-43.

Taveira, M.C. (2001). Exploração vocacional: Teoria, investigação e prática [Career exploration: Theory, research and practice]. Psychologica, 26, 55-77.

Timperley, H., Wilson, A., Barrar, H., \& Fung, I. (2007). Teacher professional learning and development. New Zealand: Ministry of Education.

Vondracek, F. W., Lerner, R. M. \& Schulenberg, J. E. (1986). Career development: A life-span developmental approach. Hillsdale, NJ: Laurence Erlbaum Associates.

Watson, M. \& McMahon, M. (2005). Children's career development: A research review from a learning perspective. Journal of Vocational Behavior, 67(2), 119-132. doi: http:// dx.doi.org/10.1016/j.jpb.2004.08.011 
Errata 1. Na edição 34.2, no artigo relato de experiência "Sensibilizar professores para o desenvolvimento de carreira dos alunos: Relato de uma experiência", da autoria de Íris M. Oliveira, Maria do Céu Taveira, e Lúcia F. Neves, faltou ser mencionado que esse contou com o apoio e financiamento da Fundação para a Ciência e Tecnologia (SFRH/BD/84162/2012). 